\title{
Sistem Pendukung Keputusan Pemilihan Mekanik Sepeda Motor Terbaik Menggunakan Metode Multi Objective Optimization on The Basis of Ratio Analysis (MOORA)
}

\author{
Suha Alvita ${ }^{1}$, Novia Intan ${ }^{1}$, Fajar Syahputra $^{1}$, Kurnia Ulfa ${ }^{2}$, Guidio Leonarde Ginting ${ }^{2}$ \\ ${ }^{1}$ Mahasiswa Program Studi Teknik Informatika STMIK Budi Darma, Medan, Indonesia \\ ${ }^{2}$ STMIK Budi Darma, Medan, Indonesia
}

\begin{abstract}
Abstrak
Dalam menentukan mekanik sepeda motor terbaik, banyak sekali kriteria-kriteria yang harus dimiliki oleh setiap mekanik sebagai syarat untuk menjadi seorang mekanik sepeda motor terbaik. Setiap masing-masing perusahaan yang bergerak dalam bidang penjualan atau service sepeda motor memiliki kriteria-kriteria untuk menentukan siapa yang akan terpilih untuk menjadi seorang mekanik sepeda motor terbaik. Pemilihan mekanik sepeda motor terbaik ini dilakukan untuk membantu meningkatkan daya kerja mekanik agar menjadi lebih baik lagi dari yang sebelumnya. Untuk membantu penentuan atau pun pemilihan dalam menetapkan seseorang yang layak menjadi seorang mekanik sepeda motor terbaik maka dibutuhkan sebuah sistem pendukung keputusan. Pada penelitian ini akan diangkat suatu kasus yaitu mencari alternatif terbaik berdasarkan kriteria-kriteria yang telah ditentukan dengan menggunakan metode Multi Objective Optimization On The Basis Of Ratio Analysis (MOORA). Penelitian dilakukan dengan mencari nilai bobot untuk setiap atribut, kemudian dilakukan proses perankingan yang akan menentukan alternatif yang optimal, yaitu mekanik sepeda motor terbaik.
\end{abstract}

Kata kunci: Sistem Pendukung Keputusan, Mekanik Terbaik, MOORA, Sepeda Motor

\begin{abstract}
In determining the best motorcycle mechanics, there are many criteria that must be owned by every mechanic as a condition to become a motorcycle mechanic best. Each of each company engaged in the sale or service of motorcycles has the criteria to determine who will be selected to become a motorcycle mechanic best. The selection of the best motorcycle mechanics is done to help improve the mechanical work to be better than the previous one. To assist in the determination or election in determining a person who is eligible to be the best motorcycle mechanic, a decision support system is required. In this research will be appointed a case that is looking for the best alternative based on criteria- $\neg$ criteria that have been determined by using the method of Multi Objective Optimization On The Basis Of Ratio Analysis (MOORA). The research is done by finding the weight value for each attribute, then done the ranking process that will determine the optimal alternative, that is the best motorcycle mechanic.
\end{abstract}

Keywords: Decision Support System, Best Mechanics, MOORA, Motorcycles

\section{PENDAHULUAN}

Sistem pendukung keputusan secara sederhana didefinisikan berupa sistem yang berbasis komputer yang digunakan untuk mempermudah dalam melakukan pengambilan keputusan. Pengunaan sistem pendukung keputusan membantu para pengambil keputusan dalam menghasilkan suatu keputusan. Hingga saat ini perkembangan metode-metode yang diterapkan pada sistem pengambil keputusan sangat pesat, dimulai dari metode yang sederhana hingga ke yang kompleks. Beberapa diantaranya metode tersebut yaitu Weighted Product (WP), Technique For Order Performance Of Similarity To Ideal Solution (TOPSIS), Weighted Aggregated Sum Product Assesment (WASPAS),Elimination Et Choix TraduisantLa Realite (ELECTRE), Multi-Objective Optimization On The Basis Of Ratio Analysis (MOORA)[1][2].

Bahkan beberapa metode saling dikombinasikan dengan metode-metode yang lain. Hal ini bertujuan agar keputusan yang dihasilkan dapat lebih tepat dan akurat, seperti metode WASPAS. Metode WASPAS merupakan kombinasi dari metode WP dan SAW[3][4].

Pada penelitian ini, metode yang digunakan yaitu MOORA. Pemanfaatan sistem pendukung keputusan dengan menggunakan metode MOORA sangat tepat jika diterapkan untuk memilih mekanik sepeda motor terbaik. Mekanik merupakan orang yang bertugas melakukan pemeriksaan, perawatan, perbaikan, penggantian suku cadang sesuai analisa Sevice Advisor yang tercantum dalam perintah kerja bengkel, dengan mengacu standarisasi pekerjaan yang telah ditetapkan. Pada penelitian sebelumnya pemilihan mekanik sepeda motor terbaik menggunakan metode (Simple Additive Weighting) SAW dan beberapa kriteria yaitu penguasaan materi, praktek meja, dan trouble shooting. Tapi tanpa disadari kriteria yang lain seperti surat teguran, masa kerja, dan pendidikan juga termasuk dalam penentuan pemilihan mekanik sepeda motor terbaik. Penggunaan beberapa kriteria tersebut, diharapkan dapat menghasilkan keputusan mekanik sepeda motor terbaik. 


\section{TEORITIS}

\subsection{Mekanik}

Menurut Kamus Besar Bahasa Indonesia Pusat Bahasa mekanik yaitu ahli mesin. Mekanik adalah orang yang ahli dalam menggunakan perangkat keras untuk memperbaiki dan merawat mesin. Kebanyakan mekanik mengkhususkan diri pada area tertentu seperti mekanik mobil, mekanik sepeda, mekanik sepeda motor, mekanik boiler, mekanik umum, pendingin udara dan pembekuan, mekanik pesawat terbang, mekanik mesin diesel[5].

\subsection{Multi Objective Optimization On The Basis Of Ratio Analysis (MOORA)}

Metode Multi Objective Optimization On The Basis Of Ratio Analysis( MOORA) adalah metode yang diperkenalkan oleh Brauers dan Zavadkas. Metode yang relatif baru ini pertama kali digunakan oleh Brauers dalam suatu pengambilan dengan multi kriteria[1]. Metode MOORA memiliki tingkat fleksibilitas dan kemudahan untuk dipahami dalam memisahkan bagian subjektif dari suatu proses evaluasi ke dalam kriteria bobot keputusan dengan beberapa atribut pengambilan keputusan. Metode ini memiliki tingkat selektifitas yang baik karena dapat menentukan tujuan dari kriteria yang bertentangan. Dimana kriteria dapat bernilai menguntungkan (benefit) atau yang tidak menguntungkan (cost).

Metode MOORA banyak diaplikasikan dalam beberapa bidang seperti bidang manajemen, bangunan, kontraktor, desain jalan, dan ekonomi. Metode ini memiliki tingkat selektifitas yang baik dalam menentukan suatu alternatif. Pendekatan yang dilakukan MOORA didefinisikan sebagai suatu proses secarabersama anguna mengoptimalkan dua atau lebih yang saling bertentangan pada beberapa kendala[2].

Langkah-langkah penyelesaian masalah menggunakan metode Multi Objective Optimization On The Basis Of Ratio Analysis (MOORA)[1][6], yaitu :

1. Buat sebuah matriks keputusan

$x=\left[\begin{array}{cccc}x_{11} & x_{12} & \cdot & x_{1 n} \\ x_{21} & x_{11} & \cdot & x_{2 n} \\ \cdot & \cdot & \cdot & \cdot \\ x_{m 1} & x_{m 1} & \cdot & x_{m n}\end{array}\right]$.

2. Melakukan normalisasi terhadap matrik $\mathrm{x}$

$x_{i j}^{*}=x_{i j} / \sqrt{\left[\sum_{i=1}^{m} x_{i j}^{2}\right](j=1,2, \ldots, n)}$

3. Mengoptimalkan Atribut

$y_{i}=\sum_{j=1}^{g} x_{i j}^{*}-\sum_{j=g+1}^{n} x_{i j}^{*}$

Apabila menyertakan bobot dalam pencarian yang ternormalisasi maka rumusnya

$y_{i}=\sum_{j=1}^{g} w_{j} x_{i j}^{*}-\sum_{j=g+1}^{n} w_{j} x_{i j}^{*}(j=1,2, \ldots, n)$

\section{ANALISA DAN PEMBAHASAN}

Dalam menentukan pemilihan mekanik sepeda motor terbaik diperlukan beberapa cara atau pun metode dalam menentukannya. Pada penelitian sebelumnya pemilihan mekanik sepeda motor terbaik menggunakan beberapa kriteria yaitu penguasaan materi, praktek meja, dan trouble shooting. Tapi tanpa disadari kriteria Surat teguran, masa kerja, dan pendidikan juga termasuk dalam penentuan pemilihan mekanik sepeda motor terbaik. Maka dari itu untuk membantu penentuan atau pun pemilihan dalam menetapkan seseorang yang layak menjadi seorang mekanik sepeda motor terbaik, dibutuhkan sebuah sistem pendukung keputusan untuk mengetahui hasil siapa yang akan menjadi mekanik terbaik.

Adapun tujuan dari sistem pendukung keputusan pemilihan mekanik sepeda motor terbaik ini adalah untuk meningkatkan semangat kerja para mekanik dan membuat mekanik lebih baik lagi dari yang sebelumnya. 
Langkah penyelesaian dalam penerapan metode MOORA (Multi Objective Optimization On The Basis Of Ratio Analysis) meliputi: Memberikan nilai setiap alternative $\left(\mathrm{A}_{\mathrm{i}}\right)$ pada setiap kriteria $\left(\mathrm{C}_{\mathrm{i}}\right)$ yang sudah ditentukan

Tabel 1. Kriteria

\begin{tabular}{|c|l|c|c|}
\hline Kriteria & \multicolumn{1}{|c|}{ Keterangan } & Bobot & Jenis \\
\hline C1 & Trouble Shooting & $30 \%$ & Benefit \\
\hline C2 & Masa Kerja & $30 \%$ & Benefit \\
\hline C3 & Pendidikan & $30 \%$ & Benefit \\
\hline C4 & Surat Teguran & $10 \%$ & Cost \\
\hline
\end{tabular}

1. Membuat matriks keputusan $X$.

2. Melakukan normalisasi terhadap matrik $\mathrm{x}$.

3. Memberi nilai bobot(W).

4. Mengoptimalkan atribut.

Bobot penilaian terhadap kriteria Trouble Shooting dan Pendidikan dapat dilihat pada tabel 2 berikut.

Tabel 2. Skala Penilaian

\begin{tabular}{|c|l|l|c|}
\hline Kriteria & Keterangan & Keterangan & Nilai \\
\hline \multirow{4}{*}{$C_{1}$} & \multirow{4}{*}{ Trouble Shoting } & Sangat Mahir & $91-100$ \\
\cline { 3 - 4 } & & Mahir & $81-90$ \\
\cline { 3 - 4 } & & Kurang Mahir & $70-81$ \\
\cline { 3 - 4 } & & Tidak bisa & $>70$ \\
\hline \multirow{3}{*}{$C_{3}$} & \multirow{3}{*}{ Pendidikan } & Strata 1 & 5 \\
\cline { 3 - 4 } & & Diploma 3 & 3 \\
\cline { 3 - 4 } & & SMA/SMK & 1 \\
\hline
\end{tabular}

Tabel 3. Data Alternatif

\begin{tabular}{|c|c|c|c|c|}
\hline Alternatif & $\mathrm{C}_{1}$ & $\mathrm{C}_{2}$ & $\mathrm{C}_{3}$ & $\mathrm{C}_{4}$ \\
\hline $\mathrm{A}_{1}$ & 90 & 3 & 3 & 1 \\
\hline $\mathrm{A}_{2}$ & 95 & 3 & 5 & 1 \\
\hline $\mathrm{A}_{3}$ & 70 & 5 & 1 & 5 \\
\hline $\mathrm{A}_{4}$ & 80 & 5 & 3 & 3 \\
\hline $\mathrm{A}_{5}$ & 90 & 1 & 1 & 3 \\
\hline $\mathrm{A}_{6}$ & 80 & 3 & 3 & 1 \\
\hline
\end{tabular}

Langkah-langkah penggunaan metode MOORA:

1. Membuat matriks keputusan $X_{\mathrm{ij}}$

$$
\mathrm{X}=\left[\begin{array}{llll}
90 & 3 & 3 & 1 \\
95 & 3 & 5 & 1 \\
70 & 5 & 1 & 5 \\
80 & 5 & 3 & 3 \\
90 & 1 & 1 & 3 \\
80 & 3 & 3 & 1
\end{array}\right]
$$

2. Normalisasi matriks $x$

$$
\begin{aligned}
& C_{1}=\sqrt{90^{2}+95^{2}+70^{2}+80^{2}+90^{2}+80^{2}=42925} \\
& \quad=207,1835 \\
& A_{11}=90 / 207,1835=0,434398 \\
& A_{21}=95 / 207,1835=0,458531 \\
& A_{31}=70 / 207,1835=0,337865 \\
& A_{41}=80 / 207,1835=0,386131 \\
& A_{51}=90 / 207,1835=0,434398 \\
& A_{61}=80 / 204,45048=0,386131 \\
& C_{2}=\sqrt{3^{2}+3^{2}+5^{2}+5^{2}+1^{2}+3^{2}=78}
\end{aligned}
$$




$$
\begin{aligned}
& =8,831761 \\
A_{12} & =3 / 8,831761=0,339683 \\
A_{22} & =3 / 8,831761=0,339683 \\
A_{32} & =5 / 8,831761=0,566139 \\
A_{42} & =5 / 8,831761=0,566139 \\
A_{52} & =1 / 8,831761=0,113228 \\
A_{62} & =3 / 8,831761=0,339683 \\
C_{3}=\sqrt{3^{2}+5^{2}+1^{2}+3^{2}+1^{2}+3^{2}=54} & =7,348469 \\
A_{13} & =3 / 7,348469=0,408248 \\
A_{23} & =5 / 7,348469=0,680414 \\
A_{33} & =1 / 7,348469=0,136083 \\
A_{43} & =3 / 7,348469=0,408248 \\
A_{53} & =1 / 7,348469=0,136083 \\
A_{63} & =3 / 7,348469=0,408248 \\
C_{4} & =\sqrt{1^{2}+1^{2}+5^{2}+3^{2}+3^{2}+1^{2}=46} \\
& =6,78233 \\
A_{13} & =1 / 6,78233=0,147442 \\
A_{23} & =1 / 6,78233=0,147442 \\
A_{33} & =5 / 6,78233=0,73721 \\
A_{43} & =3 / 6,78233=0,442326 \\
A_{53} & =3 / 6,78233=0,442326 \\
A_{63} & =1 / 6,78233=0,147442 \\
&
\end{aligned}
$$

Dari hasil perhitungan di atas maka didapat matriks ternormalisasi $\left(x_{i j}^{*}\right)$ sebagai berikut:

$$
\begin{aligned}
& \mathrm{x}_{\mathrm{ij}}^{*}=\left[\begin{array}{cccc}
0,434398 & 0,339683 & 0,408248 & 0,147442 \\
0,458531 & 0,339683 & 0,680414 & 0,147442 \\
0,337865 & 0,566139 & 0,136083 & 0,73721 \\
0,386131 & 0,566139 & 0,408248 & 0,442326 \\
0,434398 & 0,113228 & 0,136083 & 0,442326 \\
0,386131 & 0,339683 & 0,408248 & 0,147442
\end{array}\right] \\
& {\left[\begin{array}{cccc}
0,434398 & 0,339683 & 0,408248 & 0,147442 \\
0,458531 & 0,339683 & 0,680414 & 0,147442 \\
0,337865 & 0,566139 & 0,136083 & 0,73721 \\
0,386131 & 0,566139 & 0,408248 & 0,442326 \\
0,434398 & 0,113228 & 0,136083 & 0,442326 \\
0,386131 & 0,339683 & 0,408248 & 0,147442
\end{array}\right] \times \mathrm{W}_{\mathrm{j}}} \\
& \mathrm{x}_{\mathrm{ij}}^{*} \mathrm{~W}_{\mathrm{j}}=\left[\begin{array}{cccc}
0,130319 & 0,101905 & 0,122474 & 0,014744 \\
0,137559 & 0,101905 & 0,204124 & 0,014744 \\
0,101359 & 0,169842 & 0,040825 & 0,073721 \\
0,115839 & 0,169842 & 0,122474 & 0,044233 \\
0,130319 & 0,033968 & 0,040825 & 0,044233 \\
0,115839 & 0,101905 & 0,122474 & 0,014744
\end{array}\right]
\end{aligned}
$$

Tabel 4. Daftar Yi

\begin{tabular}{|c|c|c|c|}
\hline Alternatif & $\operatorname{Max}\left(\mathrm{C}_{1}+\mathrm{C}_{2}+\mathrm{C}_{3}\right)$ & $\operatorname{Min}\left(\mathrm{C}_{4}\right)$ & $Y_{i}=(\operatorname{Max}-\operatorname{Min})$ \\
\hline $\mathrm{A}_{1}$ & 0,354699 & 0,014744 & 0,339954 \\
\hline $\mathrm{A}_{2}$ & 0,443588 & 0,014744 & 0,428844 \\
\hline $\mathrm{A}_{3}$ & 0,312026 & 0,073721 & 0,238305 \\
\hline $\mathrm{A}_{4}$ & 0,408155 & 0,044233 & 0,363923 \\
\hline $\mathrm{A}_{5}$ & 0,205112 & 0,044233 & 0,16088 \\
\hline $\mathrm{A}_{6}$ & 0,340219 & 0,014744 & 0,325475 \\
\hline
\end{tabular}


Tabel 5. Hasil Rangking

\begin{tabular}{|c|l|c|}
\hline Alternatif & Result & Rank \\
\hline $\mathrm{A}_{1}$ & 0,339954 & 3 \\
\hline $\mathrm{A}_{2}$ & 0,428844 & 1 \\
\hline $\mathrm{A}_{3}$ & 0,238305 & 5 \\
\hline $\mathrm{A}_{4}$ & 0,363923 & 2 \\
\hline $\mathrm{A}_{5}$ & 0,16088 & 6 \\
\hline $\mathrm{A}_{6}$ & 0,325475 & 4 \\
\hline
\end{tabular}

Dari hasil perhitungan di atas, dapat dilihat bahwa $\mathrm{A}_{2}$ merupakan mekanik terbaik dengan nilai tertinggi. Dengan kata lain $\mathrm{A}_{2}$ merupakan mekanik terbaik.

\section{KESIMPULAN}

Dari sejumlah rangkaian analisa dan pembahasan yang telah dijelaskan, dapat diambil beberapa kesimpulan, sebagai berikut:

1. Untuk menentukan pemilihan mekanik sepeda motor terbaik bukan hanya berdasarkan kriteria keahlian, namun diperlukan juga kriteria-kriteria lain seperti pendidikan, surat teguran serta masa kerja.

2. Pemilihan mekanik sepeda motor terbaik ini menggunakan metodeMulti Objective Optimization On The Basis Of Ratio Analysis (MOORA), yang menghitung bobot nilai dari setiap kriteria-kriteria dari alternatifalternatif yang ada.

3. Penentuan mekanik yang terbaik ditentukan dari hasil perankingan yang terbaik dan dapat dipertimbangkan oleh pengambil keputusan.

\section{REFERENCES}

[1] Mesran, R. K. Hondro, M. Syahrizal, A. P. U. Siahaan, R. Rahim, and Suginam, "Student Admission Assessment using MultiObjective Optimization on the Basis of Ratio Analysis (MOORA)," J. Online Jar. COT POLIPT, vol. 10, no. 7, pp. 1-6, 2017.

[2] S. Rokhman, I. F. Rozi, and R. A. Asmara, "Pengembangan sistem penunjang keputusan penentuan ukt mahasiswa dengan menggunakan metode moora studi kasus politeknik negeri malang," J. Inform. Polinema, vol. 3, no. 4, pp. 36-42, 2017.

[3] S. Chakraborty and E. K. Zavadskas, "Applications of WASPAS Method in Manufacturing Decision Making," Informatica, vol. 25, no. 1, pp. 1-20, 2014

[4] P. Karande, E. K. Zavadskas, and S. Chakraborty, "A study on the ranking performance of some MCDM methods for industrial robot selection problems," Int. J. Ind. Eng. Comput., vol. 7, no. 3, pp. 399-422, 2016.

[5] D. P. Nasional, Kamus Besar Bahasa Indonesia Pusat Bahasa. 2008.

[6] N. W. Al-Hafiz, Mesran, and Suginam, "Sistem Pendukung Keputusan Penentukan Kredit Pemilikan Rumah Menerapkan MultiObjective Optimization on the Basis of Ratio Analysis ( Moora )," KOMIK (Konferensi Nas. Teknol. Inf. dan Komputer), vol. I, no. 1, pp. 306-309, 2017.

[7] D. Handoko, M. Mesran, S. D. Nasution, Y. Yuhandri, and H. Nurdiyanto, “Application Of Weight Sum Model (WSM) In Determining Special Allocation Funds Recipients," IJICS (International J. Informatics Comput. Sci., vol. 1, no. 2, pp. 31-35, 2017.

[8] H. Nurdiyanto and Heryanita Meilia, "SISTEM PENDUKUNG KEPUTUSAN PENENTUAN PRIORITAS PENGEMBANGAN INDUSTRI KECIL DAN MENENGAH DI LAMPUNG TENGAH MENGGUNAKAN ANALITICAL HIERARCHY PROCESS (AHP)," in Seminar Nasional Teknologi Informasi dan Multimedia 2016, 2016, no. February, pp. 1-7.

[9] J. Simarmata, Rekayasa Perangkat Lunak. Yogyakarta: Andi, 2010.

[10] M. I. Setiawan et al., "Business Centre Development Model of Airport Area in Supporting Airport Sustainability in Indonesia," J. Phys. Conf. Ser., vol. 954, no. 1, p. 12024, 2018.

[11] J. Simarmata, Pengenalan Teknologi Komputer dan Informasi. Yogyakarta: Andi, 2006

[12] G. Ginting, Fadlina, Mesran, A. P. U. Siahaan, and R. Rahim, “Technical Approach of TOPSIS in Decision Making," Int. J. Recent Trends Eng. Res., vol. 3, no. 8, pp. 58-64, 2017.

[13] A. J. Putra, L. A. Abdillah, and H. Yudiastuti, "Penentuan sekolah dasar negeri terbaik kota Palembang dengan metode weighted sum model (WSM) dan weighted product model (WPM) menggunakan visual basic.net 2015," Sentikom, no. September, pp. 1-6, 2016.

[14] S. Dian Utami Sutiksno, P. Rufaidah, H. Ali, and W. Souisa, "A Literature Review of Strategic Marketing and The Resource Based View of The Firm," Int. J. Econ. Res., vol. 14, no. 8, pp. 59-73, 2017.

[15] S. Kusumadewi, S. Hartati, A. Harjoko, and R. Wardoyo, Fuzzy Multi-Attribute Decision Making (Fuzzy MADM). Yogyakarta: Graha Ilmu, 2006. 